\title{
๑๑@@ Pobreza e educação: diálogos entre o passado e o presente, entre conformações e resistências docentes
}

\author{
André Márcio Picanço Favacho* \\ Geovana Mendonça Lunardi Mendes ${ }^{* *}$
}

\begin{abstract}
Resumo: Desde o século XIX, a pobreza tem sido objeto de governo em todos os âmbitos do Estado Brasileiro. No entanto, desde lá, a seu modo, a área educacional tem assumido fortemente essa tarefa para si, quer seja na política educacional ou na experiência docente. De fato, essa é uma questão importante, mas paradoxal. Por um lado, governam-se os pobres visando a sua liberdade; por outro, para subjugá-los. A partir de aportes teórico-metodológicos de Michel Foucault, mas também de recortes analíticos de pesquisadores do campo da sociologia da educação e da história da educação brasileira, este artigo procura estabelecer diálogo com alguns aspectos atuais da experiência docente brasileira, tentando responder se, na prática, ela é capaz de analisar esse paradoxo e de agir frente a ele. Como conclusão, o artigo sugere que a analítica de tal questão depende, enormemente, da perspicácia da política educacional e dos professores para diagnosticarem o presente e o passado da educação, para, quem sabe, experimentar novas formas de educação com as populações pobres.
\end{abstract}

Palavras-chave: Pobreza; Educação; Experiência docente.

\section{Poverty and education: dialogues between past and present, between conformations and resistance of teachers}

\footnotetext{
* Doutor em Educação pela Universidade de São Paulo (USP). Professor na Universidade Federal de Minas Gerais (UFMG). E-mail: amfavacho@hotmail.com. ORCID: https://orcid.org/0000-0002-8481-7370.

** Doutora em Educação: História, Política, Sociedade pela Pontifícia Universidade Católica de São Paulo, (PUC/SP). Professora na Universidade do Estado de Santa Catarina (UDESC). E-mail: geolunardi@gmail.com. ORCID: https://orcid.org/0000-0002-8848$\underline{7436}$.
} 


\begin{abstract}
Since the 19th century, poverty has been an object of government in all spheres of the Brazilian State. However, since then, the educational area has strongly assumed this task for itself in its own way, both in educational policy and in teaching experience. Indeed, this is an important but paradoxical issue. The poor are ruled with their freedom in mind on the one hand, and on the other, with their subjugation as an objective. Based on Michel Foucault's theoreticalmethodological contributions, but also on analytical pieces by researchers in the field of sociology of education and the history of Brazilian education, this paper seeks to establish a dialogue with current aspects of the Brazilian teaching experience, trying to answer whether it is capable of analyzing this paradox and acting upon it in practice. In conclusion, the paper suggests that the analysis of such a matter greatly depends on the perspicacity of educational policy and teachers to diagnose the present and past of education in order to possibly experiment new forms of education with poor populations.
\end{abstract}

Keywords: Poverty; Education; Teaching experience.

\title{
Pauvreté et éducation: dialogues entre le passé et le présent, entre conformations et résistances des enseignants
}

Résumé: Depuis le $19^{\text {ème }}$ siècle, la question de la pauvreté a été l'objet du gouvernement dans tous les domaines de l'État brésilien. Cependant, depuis lors, à sa manière, le domaine de l'éducation a fortement assumé cette tâche, que ce soit en matière de politique éducative ou d'expérience d'enseignement. En fait, c'est une question importante, mais paradoxale. D'une part, les pauvres sont gouvernés pour leur liberté; mais aussi d'autre part, pour les soumettre. À partir des contributions théoriques et méthodologiques de Michel Foucault, mais également d'extraits analytiques de chercheurs dans le domaine de la sociologie de l'éducation et de l'histoire de l'éducation brésilienne, cet article cherche à établir un dialogue avec certains aspects actuels de l'expérience d'enseignement au Brésil, en essayant de répondre si, dans la pratique, elle est capable d'analyser ce paradoxe et d'agir face à ce dernier. En conclusion, l'article suggère que l'analyse d'une telle question depend, énormément, de la perspicacité de la politique éducative et des professeurs à diagnostiquer le présent et le passé de l'éducation, pour, on ne sait jamais, essayer de nouvelles formes d'éducation avec les populations pauvres.

Mots-clés: Pauvreté. Éducation. Expérience d'enseignement. 


\section{Introdução}

Hoje, a fortiori, um docente brasileiro, quando se dedica a um pouco de reflexão, tenderá a dizer, mais por vivência do que por formação acadêmica propriamente dita, que a pobreza ${ }^{1}$ é um problema sério, que se configura como um obstáculo para o cumprimento da finalidade do seu trabalho educativo. Essa constatação não é de hoje e denuncia a forma como a relação sociedade-estado-educação foi construída no Brasil.

Desde o final do século XVIII, mestres denunciavam a situação de pobreza das famílias e dos alunos. No século XIX, professores se dedicavam seriamente para que as crianças pobres aprendessem as coisas da escola. Nessa mesma época, os reformadores educacionais e as elites, embora muito empenhados em ofertar escolas para as crianças pobres, defendiam que a pobreza deveria ser superada, uma vez que ela representava o atraso da nação. ${ }^{2}$ Logo, segundo esses grupos, era necessário governar os modos de ser dos pobres, em especial os modos de ser de negros e mestiços (os pobres por excelência daquela época). No século XX, a pobreza passa a ser incorporada como objeto econômico, ou seja, por meio de uma educação para o trabalho, os pobres deveriam ser educados para gerar renda. Daquele momento até os anos 1960, os corpos negros e mestiços, os corpos dos não-brancos, continuavam a ser aqueles que deveriam ser governados. No século XXI, a educação estatal tem por objetivo convencer e convocar as classes ditas menos favorecidas - outro nome dado aos pobres - a produzirem, elas mesmas, por meio de empreendedorismos, a sua sobrevivência.

Talvez o docente de hoje não saiba de tudo isso, mas ele pode e deve se perguntar: por que a escola pública é tão desprovida de materiais

\footnotetext{
${ }^{1}$ Entendemos pobreza da mesma forma que YANNOULAS (2013, p. 25), isto é, "uma situação com condicionantes que a originam e passível de transformação". Portanto, todas as vezes que nos referirmos à pobreza será sempre no sentido de situação, e não de essência. Fazemos observar também que, embora reconheçamos a importância desse debate, neste artigo, não faremos a clássica distinção entre pobreza, extrema pobreza e desigualdades; nosso intuito é trabalhar mais com o "dito" (o discurso) do que com o conceito, admitindo, assim, a pluralidade dos nomes da pobreza.

${ }^{2}$ FERNANDES (2008).
} 
pedagógicos, de recursos tecnológicos de última geração, de prédios escolares de qualidade, de boas condições salariais para os professores? Se ele estiver mais disposto, pode se perguntar também: por que a grande quantidade de avaliações externas não se converte em melhorias educativas para a escola, os alunos e os professores? Se tiver um pouco mais de sagacidade, poderia se perguntar ainda: por que os piores índices de aprendizagem se localizam exatamente nas escolas públicas de periferia, nas regiões mais pobres do país?

Ora, se os professores começarem a se fazer boas perguntas e passarem a obter boas respostas, logo verão que a posição que ocupam na escola ou na escolarização de um modo geral não é a de educadores, mas sim a de governantes de um corpo específico: o corpo dos pobres.

$\mathrm{Na}$ impossibilidade de tratar de todas as questões que estão em jogo quando o assunto é pobreza e educação, daremos visibilidade a algumas delas.

\section{Educação e pobreza ou pobreza e educação?}

Existe um debate quase permanente sobre o poder da educação para resolver os problemas da desigualdade social. Ora se espera tudo da educação ora se coloca a educação como a fonte da eterna reprodução da mesma sociedade desigual. ${ }^{3}$

Esse debate gera, entre pesquisadores, professores e gestores da educação, um dilema a respeito de qual deve ser a ênfase dessa discussão, isto é, se devemos utilizar a educação ou a pobreza como primeiro termo dessa relação.

A equação é a seguinte: se utilizarmos a educação como primeiro termo (educação e pobreza), damos a entender que ela resolveria a vida das pessoas em situação de pobreza. Se utilizarmos a pobreza como primeiro termo (pobreza e educação), vemos logo que a pobreza é um problema cuja resolução não cabe somente à educação.

\footnotetext{
${ }^{3}$ YANNOULAS (2013a).
} 
Pensar a ausência ou a negação da escolarização como responsável pela produção da pobreza faz muito sentido para muitos pesquisadores - e mesmo educadores. Ora, quanto mais pessoas analfabetas, menos desenvolvido é um país e, portanto, com mais pobreza. $\mathrm{O}$ acesso à escola é, desse ponto de vista, se não a solução para a pobreza, algo de grande importância. Todavia, interrogar essa lógica também é compreensível, pois o acesso à escola e a permanência nela não eliminou a pobreza nos países considerados ricos. Além disso, nos países pobres, a escolarização, por vezes, é vista como reprodutora das desigualdades e da pobreza. Nesse caso, a pobreza é um problema maior, que a educação pouco afeta, uma vez que ela não atinge o alvo: a redistribuição de renda.

Um grupo importante de pesquisadore ${ }^{4}$ da atualidade sobre essa temática diz que essa discussão, assim dividida, ocorre por que alguns estudiosos partem do prisma da pobreza, enquanto outros partem do prisma da educação. ${ }^{5}$ Sob o prisma da pobreza, a discussão se dá em termos de "linha da pobreza" e de como a política educacional deve atuar, nesse caso, ofertando ou ampliando o número de vagas e assumindo o compromisso de assegurar, concretamente, o direito à educação e a permanência das crianças e dos jovens na escola. Sob o prisma da educação, a discussão se dá em, pelo menos, três direções: a do fracasso escolar, a da exclusão e a da desigualdade. Do ponto de vista do fracasso escolar, advoga-se que o processo psicossocial (interações entre indivíduo e sociedade) mantém e reproduz a pobreza; do ponto de vista da exclusão, afirma-se que os alunos pobres são, ao mesmo tempo, incluídos e excluídos pelas políticas e práticas docentes; do ponto de vista das desigualdades sociais, defende-se que a pobreza é mantida porque a instituição escolar atua oferecendo oportunidades dessimétricas entre os alunos.

Depreende-se, pois, o quão difícil é definir qual a melhor perspectiva para tratar essa questão. Porém, vale a pena considerar a

\footnotetext{
${ }^{4}$ YANNOULAS; FERREIRA (2012).

${ }^{5}$ YANNOULAS (2013b).
} 
advertência do professor Miguel Arroyo $^{6}$ de que priorizar a pobreza como primeiro termo da relação tem a vantagem de nos ajudar a pensar nas razões mais profundas que a constituem, ao mesmo tempo em que pode nos ajudar a construir uma educação específica para os pobres. Específica, não no sentido de endossar as então limitadas expectativas formativas dos jovens pobres, mas, pelo contrário, no sentido de inventar maneiras mais radicais de levar professores e alunos a compreenderem como a pobreza é produzida e como eles são centrais nesse processo.

Embora essa seja uma boa reflexão, defendemos que não se trata de ofertar uma saída ou outra para essa discussão. Argumentamos que os dois prismas anteriormente mencionados pensam o problema de uma única e mesma maneira, isto é, por meio de políticas públicas. Melhor dizendo, defendem que uma política pública responsável resolveria a situação. Sem dúvida, essa é uma saída, pois as políticas públicas deveriam nos indicar os melhores caminhos. Porém, essa saída se torna limitada quando tais políticas estão longe de oferecer uma resolução para o problema.

$\mathrm{Na}$ falta de políticas públicas robustas o suficiente para resolver a questão da educação dos pobres, podemos (sem negligenciar a luta para que isso aconteça) nos ocupar em pensar as relações históricas entre educação e pobreza no Brasil. Isso significa nos darmos conta de que os pobres foram governados por meio de, pelo menos, três práticas muito bem delimitadas: uma mais localizada no século XIX e início do século XX, na qual as elites brancas e os reformadores educacionais, por mais empenhados que estivessem em oferecer a escolarização, recusavam os saberes, as culturas e o valor civilizatório dos pobres. ${ }^{7}$ Naquele momento, os pobres eram os homens livres que não encontravam trabalho, ${ }^{8}$ os negros (pós-abolição) e os não-brancos (pardos e pretos), ${ }^{9}$ sobre os quais se impunha mais ação civilizatória do que escolarização propriamente dita. Havia mais a negação da raça do que a oferta da escola, mais expropriação

\footnotetext{
${ }^{6}$ ARROYO (2017).

${ }^{7}$ VEIGA (2002).

${ }^{8}$ MELLO E SOUZA (1986).

${ }^{9}$ DÁVILA (2006); AZEVEDO (2004).
} 
do que formação. Uma segunda prática, que persistiu durante quase todo o século XX, foi a tentativa de incorporar os pobres, mais qualificadamente, na engrenagem produtiva. Para isso, era oferecida uma educação para os ofícios ou para o trabalho, quase sempre de baixa qualidade e com muitos obstáculos para ser frequentada. Na prática, a educação para o trabalho acarretou todos os incômodos que envolvem esse tipo de orientação. ${ }^{10} \mathrm{Na}$ segunda metade do século XX, surge uma terceira prática de governo dos pobres que se estende até o século XXI e tende a realocá-los em um tipo de economia que não depende mais, exclusivamente, da relação escolarização/trabalho/emprego, mas sim de qualificação, protocolos, competição e rendimentos. ${ }^{11}$

Diante disso, defendemos que, em torno da relação entre pobreza e educação (ou vice-versa), temos, mais do que prismas, práticas históricodiscursivas que foram diversas vezes evocadas no governo da pobreza ocorrido no Brasil. Tais práticas envolvem, pelo menos, três dimensões reais e suas inúmeras consequências: raça-classe, trabalho-economia, economias subjetivas. ${ }^{12}$ Por meio da dimensão raça-classe, o governo dos pobres impediu abertamente os não-brancos de participarem da vida cultural e social brasileira. Pela dimensão trabalho-economia, tal governo explorou ao máximo os pobres, sejam eles brancos ou não. Pelas economias subjetivas, aquelas que visam remuneração por competência e resultados, incitam os pobres a serem empresários de si mesmos. Tais dimensões, por meio de diversos cruzamentos discursivos ou dinamismo de uso, podem ser praticadas tanto pelo Estado quanto pelo mercado, pela política educacional, pela escola, pela docência, entre outros. Assim, pela perspectiva histórica, não cabe isolar uma dessas dimensões para fins analíticos; há que se verificar, isso sim, seu dinamismo em cada realidade

\footnotetext{
${ }^{10}$ FRIGOTTO (1998).

${ }^{11}$ Essas questões não serão tratadas aqui em detalhes. Do ponto de vista educacional, elas podem ser vistas em GADELHA (2017); de um ponto de vista mais econômico, consultar DARDOT; LAVAL (2016).

${ }^{12}$ Uma discussão semelhante a essa pode ser vista em YANNOULAS e FERREIRA (2012, p. 343). Esses autores discutem sobre "a quádrupla perspectiva (educativa, econômica, cultural e política), [podendo] ser de utilidade analisar os mecanismos específicos de discriminação que atuam na relação entre situação de pobreza e educação formal".
} 
específica. Portanto, para nós, não há lado certo nessa discussão sobre a relação entre pobreza e educação (ou vice-versa), nem o melhor prisma de análise, mas sim práticas históricas de governo dos pobres no Brasil que nos subjetivaram. Tentaremos, a seguir, mostrar algumas delas.

\section{Como governamos e educamos os pobres?}

Se consideramos a perspectiva histórica como uma boa referência para a análise da relação pobreza-educação (ou vice-versa), vale a pergunta: a qual história nos referimos? Em Foucault, ${ }^{13}$ a História não é uma ciência sacralizada ou ocupada com os grandes episódios da humanidade, tampouco concentrada nas mentalidades e comportamentos das pessoas. Por História, ele entende uma prática social capaz de mostrar as pequenas e frágeis mudanças e transformações locais, bem como relações de espanto e diferença entre o presente e o passado. ${ }^{14}$ A partir disso, diríamos, à la Foucault, em primeiro lugar, que a relação pobrezaeducação (ou vice-versa) é marcada por uma série de acontecimentos do passado, os quais hoje faríamos mais ou menos do mesmo jeito, portanto, ainda podem ser atuais. Em segundo lugar, que não repetiríamos outros acontecimentos exatamente do mesmo jeito, embora tenhamos certa consciência da existência deles. Por fim, que há acontecimentos difíceis de serem admitidos hoje em dia porque praticamos outras coisas de maneira muito diferente.

Assim, a História que defendemos exige, ao mesmo tempo, um trabalho ético sobre nós mesmos e sobre a forma pela qual temos governado o outro a partir de certas verdades historicamente construídas. Se passearmos brevemente pela história da educação brasileira, veremos que o governo das populações pobres por meio da escolarização utilizou esquemas que, ainda hoje, somos capazes de pôr em prática, ao mesmo tempo em que damos sinais de que outras formas de governo já são desejáveis ou praticáveis. Senão, vejamos.

\footnotetext{
${ }^{13}$ FOUCAULT (2000).

${ }^{14}$ FOUCAULT (2000).
} 
No início do século XIX, a noção de pobreza vigente no Brasil ainda era aquela oriunda do século XVIII, ou seja, pobres eram os homens livres vindos de fora ou nascidos no Brasil, cujo trabalho era oscilante, variante e incerto. ${ }^{15} \mathrm{O}$ pobre era, antes de tudo, um ser fabricado pela incerteza dos negócios: ora havia, ora não havia trabalho. Sem trabalho, esse homem era considerado um ser que vagava, um vadio. O pobre era um vadio! Porém, naquele momento, entendia-se por vadio um ser que não pertencia a uma classe, isto é, não era nem senhor nem escravo. Nos termos de Mello e Souza (1986), era um desclassificado; não se classificava nem em um nem em outro lugar social. Podia, também, resultar em um ser sem valor. Sendo um ser que vagava (nesse sentido, um vagabundo), o pobre do século XVIII era marcado pela sua "instabilidade social, itinerância, imediatismo, caráter provisório assumido pelos empreendimentos". ${ }^{16}$ Segundo Mello e Souza (1986), ele se torna uma figura paradoxal, ora visto como um ônus para o Estado, ora como uma utilidade. Quando não tinha trabalho, alguém precisava mantê-lo e ele era um ônus, um peso. Quando tinha trabalho, ele era útil, podendo ser explorado ao máximo, tornando-se um servo rendoso.

Essa inconstância na qual o pobre do século XVIII e XIX estava imerso, a nosso ver, produziu o simbolismo brasileiro mais marcante no governo das populações pobres até os nossos dias, a marca mais degradante que o pobre pode carregar e manifestar em seu corpo: uso e peso. Tomamos de empréstimo essas duas palavras para dizer, alegoricamente, que o governo das populações pobres no Brasil é marcado por esse simbolismo que denota, muito claramente, situações de uso, exploração, regulação, individuação, normalização, etc. Tal simbolismo ganhou diversas noções, instituições e práticas. Primeiro, para manter esse corpo vivo, os associativismos fizeram benevolências, filantropias e caridades; em matéria de educação, eles valeram-se da roda dos expostos,

\footnotetext{
${ }^{15}$ MELLO E SOUZA (1986). Apesar de esse trabalho tratar do contexto da exploração de ouro (mineração) em Vila Rica, Minas Gerais, suas conclusões são muito pertinentes para outras partes do território brasileiro da época.

${ }^{16}$ MELLO E SOUZA (1986, p. 66).
} 
das fábricas, das sociedades e agremiações educacionais, do serviço militar, entre outros. Depois, o Estado arrecadou os impostos e, em seguida, criou os grandes discursos e metas de erradicação da pobreza; ${ }^{17}$ por fim, as organizações intergovernamentais definiram uma série de usos, pesos e medidas para manter o pobre vivo. Tanto isso é verdade, que basta lembrarmos dos índices produzidos pela FAO (Órgão das Nações Unidas para Agricultura e Alimentação), que, atualmente, definem que pessoas nutridas consomem pelo menos 3.141 calorias por dia; ${ }^{18}$ dos índices monetários produzidos pela ONU/2015, segundo os quais as pessoas que estão na linha da extrema pobreza são aquelas que vivem com menos de 1,90 US\$ por dia (ou 145 reais ao mês), ${ }^{19}$ os dados do IBGE, que dizem: "atualmente, o valor do indicador de pobreza do Bolsa Família é de R \$ 89" (sic). ${ }^{20}$

Uso e peso, vistos dessa forma, isto é, como símbolo com o qual o governo marca os corpos pobres no Brasil, servem, ajustadamente, a propósitos econômicos e políticos. Eles são os rastros visíveis do que hoje poderíamos chamar de exploração e regulação. Por um lado, as populações pobres são um corpo disponível aos interesses econômicos e, por outro, uma superfície de ação política.

Tal simbolismo funcionou na organização da educação brasileira desde o final o século XIX, mas, sobretudo durante quase todo o século $\mathrm{XX}$, ele se apresentou com uma característica específica: funcionava como

\footnotetext{
17 Vale a pena conferir, notadamente, o discurso de Lyndon Johnson, de 1964, apud AZEVEDO (2005); o discurso de Robert McNamara, de 1973, apud PEREIRA (2010); os inúmeros discursos proferidos na conhecida "Conferência Nacional de Educação Para Todos", de 1990, disponíveis em: https://www.unicef.org/brazil/declaracao-mundial-sobreeducacao-para-todos-conferencia-de-jomtien-1990 (acesso em: 28.01.2020); bem como a "Declaração do Milênio", realizada no ano de 2000, disponível em: file:///C:/Users/User/Downloads/undp-br-declaracao_do_milenio.pdf (acesso em: 28.01.2020).

${ }^{18}$ Dado do Panorama da Segurança Alimentar e Nutricional 2016/Organização das Nações Unidas para a Alimentação e a Agricultura (FAO) e Organização Pan-Americana da Saúde (OPAS). Disponível em: http://www.fao.org/3/a-i6977o.pdf. Acesso em: 28.01.2020.

${ }^{19}$ Ver: https://news.un.org/pt/story/2015/10/1527191-entrevista-entenda-nova-linha-globalde-pobreza. Acesso em: 28.01.2020.

20 Ver: https://valor.globo.com/brasil/noticia/2019/11/06/extrema-pobreza-atinge-recordede-135-milhoes-de-pessoas-no-brasil-mostra-ibge.ghtml. Acesso em: 28.01.2020.
} 
um medidor rudimentar do fluxo de pessoas dentro do sistema de ensino. Ele dosava, com exatidão, a entrada, a permanência e a saída das populações no sistema escolar. Os principais elementos do uso e do peso na escolarização brasileira foram: matrícula, ensino, avaliação, estatísticas e reprovação. Tais elementos só podiam funcionar por meio de noções como grau, classe, série, etapas, admissão, entre outras. Os mais atingidos por tudo isso não podiam ser outros que não os alunos pobres, negros e mestiços.

Entretanto, na passagem para o século XXI, assistimos o desaparecimento quase total dessas noções. No lugar delas, mais do que escalonamentos ou sucessões (embora ainda existam), passamos a usar noções como diretrizes, bases, colaboração, responsabilidade, integração de sistemas, entre outras. Passamos a ter como baliza novos usos e pesos sobre a pobreza; vimos nascer orientações educativas sofisticadas que visam ao autogoverno, à aprendizagem por resultado, à resolução de problemas socioeducativos etc. Tudo indica que, por outros meios, pobres, negros ou não-brancos devem continuar a ser o alvo dessa engrenagem.

Do ponto de vista da economia estatal voltada à educação, podemos dizer que, desde a primeira metade do século XIX, uso e peso já aparecem na Constituição Imperial, de 1824. Embora essa Constituição garantisse a instrução primária gratuita a todos os cidadãos brasileiros, o que incluía "africanos, negros brasileiros, mulatos, brancos brasileiros, europeus, índios integrados", ${ }^{21}$ as populações pobres não frequentavam a escola. Acontece que, aliadas ao preconceito que as elites políticas e econômicas nutriam em relação à qualidade civilizatória dos pobres, as condições de frequência a essa escola eram tão adversas à realidade de todos eles que a escola pública se tornava mais um lugar para indigentes do que para cidadãos de direito. ${ }^{22}$ Isso era, portanto, um peso.

De acordo com Veiga (2008), durante todo o século XIX, a pobreza dos alunos era facilmente observável na falta de vestimentas adequadas e de materiais escolares, bem como na necessidade de terem

${ }^{21}$ MUSSA (1991, p. 63 apud VEIGA, 2008).

${ }^{22}$ VEIGA $(2007 ; 2008)$. 
que trabalhar. E o pior: a escola (nesse caso, uma cadeira de instrução pública) e o próprio salário dos professores eram condicionados à frequência dessas crianças; sem uma frequência mínima entre 20 e 25 crianças a escola poderia ser fechada. ${ }^{23}$ Nota-se que o Estado induzia a demanda, mas não a bancava; pelo contrário, exigia dos pobres mais esforços e mais energia. Isso era, portanto, um uso.

Com a Abolição, no final do século XIX, como se já não bastassem os pobres existentes, os escravos libertos engrossaram a pobreza. Naquele momento, os pobres deixaram de ser apenas os homens livres que não tinham trabalho e passaram também a ser os negros e os mestiços livres ou libertos sem trabalho. As elites e o poder público da época não se interessaram em ampliar a escola frente a essa realidade. ${ }^{24}$ Para piorar a situação, além dos negros e mestiços adultos, uma nova geração de pobres se formava: as crianças pobres negras e mestiças, essas que seriam os sujeitos por excelência da escolarização nascente. ${ }^{25}$

Essas crianças sofriam o preconceito da cor e da desigualdade de oportunidade escolar. Embora tivessem a garantia de que o Estado ofereceria a instrução primária de maneira gratuita, essa situação era irregular. Bruno Komatsu e outros $(2019)^{26}$ nos esclarecem que, na realidade, o acesso à educação pública era restrito às elites, aos brancos com certa condição econômica, dadas as dificuldades dos demais para frequentar a escola - situação que "relegou nativos americanos, negros e mestiços ao segundo plano". ${ }^{27}$ Para os autores, isso é o resultado da estrutura desigual do poder político e da maneira corporativa como as regiões mais ricas e industrializadas eram atendidas em detrimento das demais. Isso era, portanto, uso e peso.

Dávila (2006), na linha do debate racial, em seu primoroso estudo Diploma de Brancura - política social e racial no Brasil - 1917-1945, nos revela que as elites branca, médica, científico-social e intelectual

\footnotetext{
${ }^{23}$ VEIGA (2008).

${ }^{24}$ BRAGA; MAZZEU (2017).

${ }^{25}$ SCHUELER (1999); CUNHA (2016).

${ }^{26}$ KOMATSU e outros (2019).

${ }^{27}$ KOMATSU e outros (2019, p. 691).
} 
emergentes no período mencionado imprimiram suas conjecturas sobre raça na política educacional. Na visão do autor, os médicos, intelectuais e reformadores educacionais não disfarçavam o valor supremo da brancura em relação à negritude, herança de uma colonização que imprimiu na nossa cultura a suposta superioridade dos brancos ou dos europeus sobre os negros.

O mesmo autor diz, ainda, que, para além do período estudado, desde a década de 1960, a educação pública brasileira tem se baseado em classes sociais. Os pobres vão às escolas públicas e os ricos às escolas particulares. Entretanto, defende que a raça foi, por excelência, a metanarrativa da sociedade brasileira que influenciou as demais metanarrativas, como gênero, sexualidade, classe social e nacionalidade. Para ele, naquele período estudado, a educação brasileira, por meio de suposições de raça, sustentadas por práticas eugênicas, impeliu as crianças negras, não-brancas e pobres a abandonarem a escola elementar nos três primeiros anos.

Por todo o século XIX e XX, o Estado Brasileiro manteve uma intensa discussão sobre a educação dos brasileiros e, em especial, das populações pobres, porém, sempre de maneira controversa. Ora como peso, ora como uso, ora como peso e uso. Durante todo esse período, entretanto, a medida que prevaleceu, de fato, única, duradoura e frágil, foi a obsessão estatal por certa política educacional que destinava as populações de pobres, negros e mestiços ao trabalho, com prevalência do uso ou da exploração do trabalho dessas pessoas. Primeiro, nos estabelecimentos militares, nas oficinas, nas escolas de aprendizagem de ofícios; mais tarde, no ensino profissional e no sistema $\mathrm{S} ;{ }^{28}$ hoje, nos incentivos financeiros e fiscais para o primeiro emprego (PNPE). ${ }^{29}$

Em matéria de educação, o Estado Brasileiro, negligenciando ou racionalizando, tem negado às populações pobres os níveis mais elevados de educação, sob o pretexto de não poder arcar com os custos ou de que defende a meritocracia. Desde o início, negou o Ensino Secundário, o

\footnotetext{
${ }^{28}$ MÜLLER (2010).

${ }^{29}$ BRITO (2006).
} 
Segundo Grau (hoje chamado Ensino Médio) e, claro, negou também o Ensino Superior. ${ }^{30}$

Se um professor engajado atualmente fosse indagado sobre como educa os alunos pobres e, por ventura, ignorasse as práticas históricas, essas que acabamos de elencar, pelo menos ele saberia dizer do esforço que faz para manter as crianças e jovens na escola. Diria ele: i) me esforço para que as crianças e jovens não abandonem a escola; ii) tento oferecer um conteúdo escolar mais próximo da realidade emocional e social deles e de suas comunidades; iii) enfim, me esforço para gerir suas contendas e dilemas.

Ora, os esforços desses professores, em parte, são exatamente uma resposta possível à forma como o Estado Brasileiro tem governado historicamente as populações pobres: como peso e uso ou, se quiserem, regulação e exploração.

\section{Experiência docente e pobreza}

Se o Estado Brasileiro assim tem governado os pobres, uma importante questão pode ser agora verificada: a maneira estatal de governar a pobreza contagiou a experiência docente?

Antes de arriscar uma resposta, gostaríamos de dizer que, por experiência docente, não concebemos a estrita atividade realizada pelo professor na escola ou na sua sala de aula com os seus alunos, e sim como ele se vincula ética e politicamente aos saberes historicamente concernentes à docência.

Posto isto, vale a pena dedicar algumas linhas à experiência docente construída e praticada no Brasil. Em geral, ela tem sido utilizada pelo Estado como uma das formas para integrar a população às exigências estatais. Ora, o Estado necessita da escola e dos professores para cumprir suas metas. Ocorre que, nesse ponto, é necessário antes separar e, em seguida, relacionar experiência docente e escolarização.

${ }^{30}$ BUFFA; NOSELLA (1997); NUNES (2000); SPOSITO (1984). 
A escolarização é a estrutura maior e mais completa por meio da qual é possível integrar os indivíduos ao Estado. Tal estrutura data do século XIX e, desde então, se tornou o vetor central pelo qual passa quase tudo, desde a alfabetização das massas até campanhas de vacinação e a famosa promessa brasileira de que salvar as crianças é salvar o Brasil. ${ }^{31}$ Isso se dá porque, de acordo com as teorizações de M. Foucault, a escolarização é, na realidade, um dispositivo de poder. O dispositivo ${ }^{32}$ é entendido pelo filósofo não como um ato de violência (simbólica ou não), mas, por um lado, como o trabalho de justificativa teórica, cientifica, filosófica, moral, entre outras; por outro lado, como um jogo de poder sobre os indivíduos, a fim de produzir saberes que condicionam suas atitudes; por outro lado, ainda, como uma estratégia radical que visa atender certas urgências políticas, econômicas, sociais etc., em um dado momento histórico.

Como todo dispositivo, o de escolarização é composto de saberes, poderes e estratégias, sendo suficientemente potente para integrar os indivíduos ao Estado. Ele atende uma das mais importantes urgências políticas desde o século XIX, a saber: controlar e disponibilizar para as populações os diferentes discursos, desde que balizados por critérios que separam e diferenciam o normal do anormal. ${ }^{33}$ Essa baliza permite separar o letrado do analfabeto, mas, mais do que isso, separa (e relaciona) o civilizado do bárbaro, o produtivo do improdutivo, o são do louco, o correto do delinquente, entre outros. Foucaultianamente, trata-se de critérios vindos, entre outros lugares, da Medicina, da Psiquiatria, do Direito, das Ciências Humanas e do próprio Estado. Não se trata de monopólio do Estado sobre a educação, mas da pulverização dos saberes considerados válidos ou normais por todo o tecido social. Ocorre que os dispositivos não são coerentes, e sim contraditórios. O dispositivo de escolarização, por exemplo, ao mesmo tempo em que deseja que as pessoas sejam capazes de pensar e agir cientificamente, também produz

\footnotetext{
${ }^{31}$ RIZZINI (2011).

${ }^{32}$ FOUCAULT (2000).

${ }^{33}$ FOUCAULT (2001).
} 
um efeito contrário quando utiliza as técnicas científicas de controle e normalização sobre os indivíduos, em lutas e dominações nem sempre claras e que não cessam. Ou seja, se a urgência política, por um lado, pede à escolarização a produção de um pensamento autônomo, cientifico, coerente, por outro, demanda a produção de um sujeito normalizado, civilizado, obediente, produtivo, meritocrático, etc.

É no interior desse paradoxal dispositivo que a experiência docente se encontra. Nesse lugar, ela atua como um diagrama complexo, que pode, entre outras coisas, ponderar, assegurar, avaliar, distorcer, ajustar, resistir, modificar, alterar, negociar, dialogar, etc. Agindo dinamicamente, ela pode estabelecer múltiplos diálogos ou negociações com a escolarização, seus sujeitos e interessados: alunos, professores, famílias, comunidades, governos, empresas, organizações não governamentais, sindicatos, movimentos sociais, universidade, partidos políticos, mídias e tudo mais que possa lhe interessar.

Como essa experiência foi constituída? Desde o século XIX em diante, a experiência docente tem se manifestado por meio de, pelo menos, quatro formas históricas mais gerais: sacerdotal, médico-psicológica, política e gestora. ${ }^{34} \mathrm{~A}$ forma religiosa diz respeito ao fato de a docência, há muito, estar associada, ao mesmo tempo, ao problema divino e moral. Ao que tudo indica, a experiência sacerdotal obteve grande reconhecimento social e político até fins do século XIX, razão pela qual o referente docente era similar ao saber sacerdotal, ao oficio de sacerdócio; professor e o padre serviram mutuamente de espelhos para a docência. Quanto à experiência médico-psicológica, ela aparece no final do século XIX e se estende largamente dentro do século XX. Nesse caso, o referente é muito mais o saber médico do que o saber religioso, mas sem excluí-lo. Apenas para citar exemplos de suas realizações, durante essa experiência, se desenvolveram, pelo menos, duas importantes estratégias educativas: a pedagogia experimental e os conhecidos testes de inteligência. A seu

${ }^{34}$ RODRÍGUEZ-AMAYA (2017 e 2019); FAVACHO (2013, 2018) 
turno, a experiência política ${ }^{35}$ elege como seu referente as lutas por uma educação democrática, científica e produtiva. Seu referente está mais próximo do saber político do que do saber médico ou sacerdotal, ainda que não os exclua. No Brasil, os conhecidos Pioneiros da Educação Nova, cujo primeiro manifesto data de 1932, fruto do movimento internacional pela educação ocorrido na década de 1920, dão uma boa prova desse tipo de experiência docente. Ela não se ocupava apenas com a alma ou corpo biológico dos estudantes, mas também com a atualidade econômica, política e cientifica de uma população livre e produtiva. Por fim, temos a experiência gestora que, ao que tudo indica, surge na segunda metade do século $\mathrm{XX}$ e, desde lá, tem também conduzido a docência por meio do saber empresarial.

Essa é a razão pela qual as figuras do padre, do médico, do político e do empresário têm, por vezes, emprestado elementos para compor as faces da docência. Assim, como era de se esperar, a docência se valeu dos saberes religiosos, médicos, políticos e, mais recentemente, empresariais ou imiscuiu-se neles. Entre essas quatro formas da docência não há uma hierarquia que definiria a mais importante; pelo contrário, elas emergem concomitantemente, proliferando múltiplas possibilidades de docência. E é a essa experiência histórica que podemos atribuir o caráter múltiplo da docência.

Retornando à pergunta deixada lá atrás - a maneira estatal de governar a pobreza contagiou a experiência docente? -, a resposta é complexa. Em primeiro lugar, porque, assim como o dispositivo de escolarização, a experiência docente, independente dessas quatro formas mais gerais, não abandonou a vontade de normalizar os alunos (pobres ou não). Tal normalização, como nos mostrou Veiga-Neto (2004), se dá, entre outras coisas, por meio de prescrições didáticas e curriculares. ${ }^{36}$ Isso revela

\footnotetext{
${ }^{35}$ Todas as experiências são políticas, obviamente. Porém, o que chamamos de política aqui é o fato de o momento histórico em que ela aparece ser marcada pela necessidade de se construir uma sociedade democrática com a participação real da escola pública.

${ }^{36}$ VEIGA-NETO (2004).
} 
que, na experiência docente, também está presente o paradoxo do pensamento autônomo versus práticas de normalizações.

Em segundo lugar, porque, também como o dispositivo da escolarização, a experiência docente, em qualquer uma das suas quatro formas, policiou os alunos para que eles se abrigassem na escola, seja pela obrigatoriedade da matrícula, seja pela promessa de que dias melhores viriam, seja simplesmente porque ali, na escola, bem ou mal, é melhor que na rua.

Em terceiro lugar, é digno de nota, a experiência docente, em nenhuma de suas diversas formas, concordou que a educação dos pobres fosse um peso ou um uso. Pelo contrário, ela assumiu, por diversas vezes, o tal peso, seja por piedade cristã, colaboração médica na urbanização das cidades, apoio político ou inserção dos jovens aos mercados; a experiência docente dividiu com os pobres o peso de educá-los. Entre outras várias ações, recebeu crianças e jovens entregues nas escolas de ofícios, recebeu crianças sem roupas e descalças nas escolas primárias, inventou formas diversas de acolhimento dos alunos que repetiam uma série seguidas vezes, inventou formas de alongar o tempo deles dentro da escola, flexibilizou as formas de avaliação, parcelou suas notas etc. Não obstante essa possível divergência com o Estado, a experiência docente afinou-se com o dispositivo de escolarização em um ponto: não tolerou o jovem preguiçoso, mentiroso e criminoso. Frente ao crime ou à deliquência, a experiência docente tende ou volta a ser estatal. De certa maneira, isso mostra que as relações de poder, seja da parte do estado ou da docência, tendem a se remeter mutuamente.

Em quarto lugar, exatamente por não tolerar crianças e jovens deliquentes - em geral, pobres e negros (ou não-brancos) -, a experiência docente manteve dúbia a tarefa de educar os pobres: por um lado, deseja libertar os alunos de sua condição de pobreza, ajudando-os no que pode, mas, por outro, os mantém sob vigilância. Dessa maneira, justificamos nossa desconfiança de que a experiência docente, embora não tenha tomado a educação do pobre como um peso, como um custo para os cofres do Estado, ou como um uso, uma utilidade, ainda não a concebeu 
suficientemente como um direito: o direito à educação. Mas isso também possui uma história. Vejamos.

\section{Direito à educação e direito à aprendizagem}

A Declaração Universal dos Direitos Humanos, de 1948, determina, em seu artigo 26, que

[...] toda a pessoa tem direito à educação. A educação deve ser gratuita, pelo menos a correspondente ao ensino elementar fundamental. O ensino elementar é obrigatório. $\mathrm{O}$ ensino técnico e profissional dever ser generalizado; o acesso aos estudos superiores deve estar aberto a todos em plena igualdade, em função do seu mérito. ${ }^{37}$

Existe, no referido artigo da Lei, pelo menos três palavras da maior importância para mundo educacional: direito, gratuidade e obrigatoriedade. Mais do que palavras, são noções; mais do que noções, são lutas, lutas sociais. Não iremos aqui tratar de todas essas lutas e nem aprofundá-las, apenas desejamos destacar para o leitor a seguinte questão: tomando por base perspectivas analíticas seguras ${ }^{38}$ a respeito das noções destacadas, no Brasil, começamos a falar, primeiro, de gratuidade; depois, de obrigatoriedade; por fim, de direito. Na realidade, diz Horta (1998), os reformadores tropeçavam nessas lutas. Ora aprovavam, ora retiravam, ora misturavam uma luta na outra - como foi o caso do debate que identificava gratuidade com obrigatoriedade -, ora retrocediam no entendimento sobre certa luta - como o absurdo de defender a obrigatoriedade da educação apenas da parte do aluno.

A começar pela gratuidade, ela foi incorporada na Constituição Imperial de 1824, cujo artigo 179 trata da "inviolabilidade dos Direitos http://www.direitoshumanos.usp.br/index.php/Declara\%C3\%A7\%C3\%A3o-Universal-dosDireitos-Humanos/declaracao-universal-dos-direitos-humanos.html. Acesso em: 04.02 .2020

${ }^{38}$ Horta (1998); CURY (2000; 2008). 
Civis, e Políticos dos Cidadãos Brazileiros, que tem por base a liberdade, a segurança individual, e a propriedade, é garantida pela Constituição do Imperio, pela maneira seguinte". ${ }^{39} \mathrm{Um}$ pouco antes da assinatura do Imperador, está expresso: “A Instrucção primaria, e gratuita a todos os Cidadãos". 40

Posta dessa maneira, isto é, ao final da Lei, tudo indica que era assim mesmo que se desejava tratar a gratuidade, pois o Ato Adicional de 12 de agosto de $1834^{41}$ confirmou o lugar que a gratuidade deveria ocupar, estabelecendo que as províncias passavam a ter a competência para legislar sobre a instrução pública e criar estabelecimentos de ensino próprios. $\mathrm{Na}$ prática, isso significava que cada província passava a garantir ou não a gratuidade que, obviamente, ficava prejudicada devido às condições financeiras de cada localidade. Ainda segundo Horta (1998), em razão dessa situação, a gratuidade desaparece da Constituição de 1891, só reaparecendo na Constituição de 1934.

Quanto à obrigatoriedade, Horta (1998) nos mostra que ela já aparecia no discurso de algumas autoridades da educação desde 1854, porém nenhuma importância efetiva lhe fora dada. A razão era a mesma, ou seja, a obrigatoriedade, assim como a gratuidade, impunha ao país uma obrigação que ele dizia não ter recursos para manter. Mais tarde, na Constituição de 1891, tanto a gratuidade quanto a obrigatoriedade desaparecem da Lei, embora ficasse preservado o entendimento de que elas ficariam a cargo da instância federativa que agora passava a se chamar estado, a depender de suas condições. Instaura-se sub-repticiamente a política "o estado que puder que o faça", iniciando-se, assim, as

\footnotetext{
39 Escrito conforme a grafia da época. Disponível em: http://www.planalto.gov.br/ccivil_03/Constituicao/ Constituicao24.htm. Acesso em: 04.02 .2020

${ }^{40}$ Idem

${ }^{41}$ Horta (1998).
} 
conhecidas desigualdades regionais em relação à oferta de educação pública. $^{42}$

Segundo Horta (1998), na Constituição de 1946, a rigor, ninguém mais era contra a gratuidade e a obrigatoriedade do ensino, uma vez que já se compreendia que uma não funcionaria sem a outra. Porém, infelizmente, o Estado Brasileiro ainda se esquivava da sua obrigação, defendendo o argumento de que a obrigatoriedade era para o aluno e não para ele. Segundo o autor, a obrigatoriedade só irá ganhar status de obrigação do Estado na Lei de Diretrizes e Bases da Educação de 1961.

Quanto ao direito à educação, ele é uma nova página na educação pública brasileira. Sempre com Horta (1998), destacamos que tal direito, embora já mencionado na Constituição de 1934, só se configura na LDB de 1961. Todavia, é somente na Constituição de 1988 que ele se torna uma realidade definitivamente constitucional. Foi em 1988 que a educação passou a ser concebida como um serviço público a ser ofertado pelo Estado. E mais: se isso não acontecer, a própria pessoa pode exigir que a Lei se efetive e é em razão disso que o direito à educação é um direito público subjetivo. ${ }^{43}$ Fica estabelecido, portanto, que a educação é direito de todos, dever do Estado e da família e deve ser gratuita e obrigatória. Essas premissas estão expressas no Estatuto da Criança e do Adolescente, de 1990, e na LDB de 1996.

Essa breve introdução à legislação brasileira, sem grandes aprofundamentos teóricos ou políticos, serve apenas para dizer, sobretudo ao jovem professor, que o direito à educação, no Brasil, se apresenta tardiamente como uma tarefa de Estado. Portanto, trata-se de uma conquista. O direito, a gratuidade e a obrigatoriedade, nos termos da Constituição de 1988, fecham um ciclo de mais de um século e meio de luta, se considerarmos o intervalo entre 1824 e 1988. A esta altura, cabe a pergunta: o direito à educação se efetiva atualmente?

\footnotetext{
${ }^{42}$ Para averiguar as atuais desigualdades de aprendizagem de acordo com regiões, gênero, etnias e raça no Brasil, ver dados de 2018 do Fundo das Nações Unidas para a Infância. Disponível em: http://www.trajetoriaescolar.org br. Acesso em: 09.03.2020.

${ }^{43}$ CURY (2000).
} 
$\mathrm{Na}$ verdade, a luta não acabou. Mais recentemente, temos sido acometidos pela irrecusável luta por um outro direito: o "direito à aprendizagem". Mas o que é isso? É o direito do aluno de aprender. A LDB de 1996 não só defende esse direito como não o dissocia do direito à educação. Defende, em seu "art. $3^{\circ}$, XIII - garantia do direito à educação e à aprendizagem ao longo da vida". 44 Acontece que, em geral, o direito à aprendizagem tem sido muito utilizado pelas avaliações nacionais e internacionais de estudantes $^{45}$ para estabelecer metas, objetivos, habilidades e competências a serem apreendidos pelos alunos e ensinados pelos professores. Essas avaliações, embora possam ser importantes para fornecerem diagnósticos relevantes de aprendizagem ou de contextos socioeconômicos, tendem, no final das contas, a privilegiar a aprendizagem, ${ }^{46}$ considerando pouco o fato de que o efetivo direito à educação é o portal seguro para o direito à aprendizagem.

Quando essa inversão se dá, ou seja, quando a prioridade recai sobre os produtos do ensino em detrimento das condições objetivas de trabalho e da qualidade que uma educação deve ter - seja por crença na técnica ou por usos políticos -, o resultado é um conjunto de medidas que nem sempre colaboram com a educação dos pobres. Medidas como a elaboração da $\mathrm{BNCC}^{47}$ ou de programas de Alfabetização, como o PNAIC, ${ }^{48}$ entre outras, podem ser válidas em muitos aspectos. Mas, quando são confrontadas com a realidade educacional do país, revelam que as escolas não possuem boas estruturas pedagógicas, prediais e sanitárias; que os professores não gozam de bons salários e carreiras; e que os alunos não são assistidos de maneira plena. De forma que, ao ignorar esses elementos, os sistemas escolares tendem a negar o direito dos alunos a uma boa escola, àquela que o mundo desenvolvido mostrou só ser possível com um sistema escolar robusto em todos os sentidos. Quando uma política

\footnotetext{
${ }^{44}$ http://www.planalto.gov.br/ccivil_03/leis/19394.htm. Acesso em: 09.03.2020.

45 Nacionalmente, é o caso da Prova Brasil, entre outras; internacionalmente, o maior exemplo é o Programa Internacional de Avaliação de Estudantes (PISA).

${ }^{46}$ BIESTA (2013).

${ }^{47}$ Base Nacional Comum Curricular.

${ }^{48}$ Pacto Nacional pela Alfabetização na Idade Certa.
} 
educacional age nessa direção de minimizar o direito à educação, ela obriga a escola e seus professores a apresentarem bons resultados de aprendizagem, exigindo deles mais dedicação, trabalho e competência, apesar das condições objetivas de ensino. ${ }^{49}$

Nesse sentido, a exigência de metas e resultados de aprendizagem se revela um obstáculo ao direito à educação. Em vez de ser um mecanismo que ajuda a ampliar a presença do Estado na educação - no sentido de bancar uma educação pública, obrigatória, laica, democrática e de qualidade -, tal exigência força o professor e os alunos a uma austeridade de trabalho que ultrapassa o que se pode fazer. ${ }^{50}$ Mais uma vez, o Estado racionaliza a educação pública dos pobres, oferecendo novas medidas, novos pesos, avaliando se o retorno do que oferta é vantajoso ou não. Gentili (2009) ${ }^{51}$ nos faz ver que, infelizmente, o direito à educação se transformou em um discurso falacioso, não só porque muitos o defendem nos momentos de crise, fazendo dele a promessa de felicidade, mas também porque, de maneira inimaginável, ele foi utilizado "como o argumento que condenava ao sótão da história toda associação entre educação e cidadania, educação e política, educação e igualdade". ${ }^{2}$

\section{E as resistências, como pensá-las?}

A partir das contribuições foucaultianas sobre a noção de resistência, adotamos o pressuposto de que a mesma não é externa ao poder, mas que ela o compõe. Isso significa dizer que a resistência só pode resistir se souber, em primeiro lugar, localizar, transversalmente, as táticas e as estratégias utilizadas pelo poder, mas também se souber localizar, de maneira específica, onde ela mesma se situa nessa trama.

No caso da relação entre pobreza e educação (ou vice-versa), podemos dizer que o transversal, isto é, o que atravessa o Estado e a

\footnotetext{
${ }^{49}$ LUZ (2017).

${ }^{50}$ DARDOT; LAVAL (2016).

${ }^{51}$ GENTILI (2009).

${ }^{52}$ IDEM (p. 1074).
} 
experiência docente, é o procedimento que individualiza e totaliza o sujeito. Para Foucault (2003a e 2004a), as técnicas de individualização e os procedimentos totalizantes definem o que poderíamos chamar de Estado Moderno. ${ }^{53}$ Em outras palavras, ao mesmo tempo em que o Estado governa a população em geral por meio de estatísticas, economia e dispositivos de segurança, ${ }^{54}$ ele convoca os saberes e as instituições a individualizar as condutas dos sujeitos em seus contextos específicos. No que concerne ao objeto deste artigo, o Estado governa a população em geral, enquanto, por meio de saberes e instituições, atua de maneira especifica sobre os pobres.

Quanto a saber onde a resistência se situa na trama do Estado, trata-se de ela mesma reconhecer o ponto exato em que se constitui histórica, ética e politicamente. Como tentamos dizer, esse ponto é aquele que denominamos experiência docente, isto é, o vínculo ético-político por meio do qual os professores agem sobre os jovens pobres. Vínculo que, historicamente, tem se dado por meio de saberes religiosos ou humanistas, normalizadores, políticos e mercadológicos. Por meio de visões religiosas ou humanistas, tornam a escola um lugar de socialização; por meio de visões normalizadoras, pretendem enquadrar os alunos nas normas externas de comportamento e conhecimento; por meio de saberes políticos, desejam que os alunos sejam críticos da sociedade; por meio de visões mercadológicas, desejam que os jovens sejam profissionalizados o quanto antes. Se essa é a especificidade da experiência docente, o máximo que ela tem oferecido aos alunos pobres é apaziguar as suas contendas, utilizando o que estiver ao alcance das suas mãos: socializações, humanismos, criticidades e incentivos ao trabalho.

Desse modo, se o Estado age sobre a população, individualizando e totalizando os corpos, a experiência docente, por sua vez, age tentando aplacar as paixões dos indivíduos. A questão é saber se, no final das contas, esses dois lados não se encontram em uma única e mesma ação. Por isso, perguntamos: os dois lados se especializaram em governar os

\footnotetext{
${ }^{53}$ FOUCAULT (2003a; 2004a).

${ }^{54}$ FOUCAULT (2003b).
} 
estudantes pobres para fins não explícitos? Ora, o que é governar para fins não explícitos?

Como vimos ao longo deste artigo, ainda que brevemente, em nenhum momento da história educacional brasileira se presenciou, de fato, um projeto educativo para essas populações. No âmbito do Estado Brasileiro, esse vazio fica evidente: no fundo, pretende-se que as populações pobres estejam disponíveis para as necessidades flutuantes dos mercados; mercados, todos sabem, de pouco valor formativo, humano e remunerativo. No âmbito da docência, o não explícito se revela na medida em que as ações docentes se limitam, o que é muito, às necessidades mais urgentes dos alunos.

Mas, então, é possível a resistência? Sim, desde que nunca a entendamos como algo total ou global, mas sempre local e específica, ${ }^{55}$ tanto no sentido de não querer jogar o jogo de uma certa dominação nesse caso, a do Estado -, como no sentido de nos livrarmos daquilo em que nos tornamos - aqui, referimo-nos à experiência docente. Nessa direção, a natureza da luta na docência poderia ser traduzida de duas formas. Uma seria a luta contra a maneira pela qual o Estado governa os pobres, o que significa não aceitar e não jogar o jogo dos pesos, das medidas e dos usos. A outra seria uma luta contra nós mesmos, nesse caso, contra o tipo de docência que praticamos, geralmente impregnada de saberes religiosos, médicos, políticos e empresariais. Quanto mais a docência souber se autoavaliar, mais ela será capaz de focar no que há de mais essencial em sua resistência, mais ela saberá se concentrar no ponto certo ou, se quiserem, no ponto cego, lá onde se deve dispensar o máximo de atenção, uma vez que é lá o ponto onde as longas durações éticopolíticas da docência depositaram suas formas.

Não temos a pretensão de enumerar nem de comprovar formalmente as resistências praticadas pela docência, não se trata disso. Mas é importante frisar que há fortes indicativos de que os professores

\footnotetext{
${ }^{55}$ FOUCAULT (1988).
} 
engajados têm praticado a educação junto a crianças e jovens pobres de uma das três formas descritas a seguir. ${ }^{56}$

A primeira forma se dá pelas lutas ou engajamentos identitários, geralmente praticada por professores que, a partir de questões de gênero, classe, sexualidade, etnia e raça, buscam produzir em seus alunos sentidos para viver a escola. Esses professores partem do princípio de que, infelizmente, os lugares onde os alunos moram são ou podem ser violentos e que eles convivem com situações humilhantes - entre as quais estão a violência doméstica, o tráfico de drogas, a gravidez na adolescência e o desemprego. Segue-se a isso a forte confiança de que a escola pode fazer algo por eles. Em geral, para esses professores, a pobreza se apresenta de duas maneiras. A primeira é na direção de algo catastrófico, isto é, em razão da ausência do estado, tudo de ruim que existe acontece no lugar onde essas crianças e jovens moram e, exatamente por isso, há necessidade de fornecer informações gerais e atuais a essas populações. A segunda maneira vai na direção do que eles podem fazer pelos alunos. A pobreza desperta nos professores uma obrigação moral de alertar esses alunos dos riscos que correm e protegê-los, se necessário, de suas próprias comunidades. Os professores do engajamento identitário pretendem que os alunos se reconheçam pobres, negros e postergados pelas políticas públicas. No entanto, o limite desse tipo de engajamento é exatamente esse, ou seja, encontra-se encastelado aos temas das identidades, o que, no limite, pode, mais uma vez, ser um excesso de governo sobre os jovens pobres. $^{57}$

A segunda forma é exercida por professores que, com base nos discursos globais, reúnem os alunos em torno de lutas ambientais ou ecológicas. É um engajamento que não se dá por meio de uma identidade, como o anterior. Pelo contrário, é um engajamento que se dá de fora para dentro. Isso se comprova na medida em que esses professores privilegiam os temas globalizantes; temas que se caracterizam por lançarem os sujeitos para as questões mundiais e suas relações com as questões locais; também

\footnotetext{
${ }^{56}$ FAVACHO (2019).

${ }^{57}$ DUARTE (2016).
} 
são temas humanitários, aqueles que fazem forte apelo para que, no caso da escola, os alunos se ajudem mutuamente. Há professores que são defensores ferrenhos do meio ambiente e/ou dos trabalhos comunitários. Isso se reflete, cita o autor, ${ }^{58}$ nos temas dos brasileiros finalistas do prêmio Global Teacher Prize - considerado o prêmio Nobel da Educação. O finalista de 2015, por exemplo, diz que trabalhou com a "utilização da casca da castanha de baru, típica do cerrado da região (MT), para fazer pisos e a utilização de resíduo de soro de queijo para enriquecer pães e dar mais qualidade à alimentação". ${ }^{59}$ O finalista de 2017 trabalhou com a recuperação da água do Rio Doce. A finalista de 2019 apresentou um projeto de robótica construído, segundo ela, "com materiais de sucata, como garrafas, tampinhas e canudos [servindo] como ferramentas para construir carrinhos e brinquedos automatizados". 60 Ainda segundo o mesmo estudo, ${ }^{61}$ para esses professores, a pobreza se apresenta como o espaço onde se pode experimentar práticas colaborativas, voluntariadas e humanitárias. O limite desse tipo de prática docente é não problematizar a produção da pobreza e ainda acreditar que essa mesma pobreza será superada por consensos mundiais ou locais.

E, por fim, a terceira forma é desempenhada por professores que convidam os alunos a experimentarem empreendedorismos sociais e/ou economias solidárias. Para o autor desse estudo, ${ }^{62}$ em geral, nas escolas públicas ou privadas mais bem equipadas e nas escolas do sistema $\mathrm{S}$, tais atividades extrapolam a simples prática lúdica de ensino sobre mercados. Nelas, a tendência é experimentar o empreendedorismo, especialmente no campo da programação e da robótica. Diferentemente, nas escolas públicas comuns, escolas sem nenhum projeto especial financiado, esse engajamento econômico se reduz a oferecer os rudimentos de uma

\footnotetext{
${ }^{58}$ FAVACHO (2019).

59 Disponível em: http://agenciabrasil.ebc.com.br/educacao/noticia/2015-12/professorbrasileiro-e-finalista-do-global-teacher-prize. Acesso em: 01.08.2019

60 Disponível em: http://porvir.org/global-teacher-prize-2019-tem-dois-professoresbrasileiros-entre-os-50-finalistas/. Acesso em: 01.08.2019.

${ }^{61}$ FAVACHO (2019).

${ }^{62}$ FAVACHO (2019).
} 
economia doméstica. Apesar dessas diferenças, no geral, esses professores parecem acreditar que basta saber orientar bem os alunos nas possibilidades atuais dos mercados para superar a pobreza.

Os limites dessas práticas ou lutas estão, sobretudo, no fato de nem sempre interrogarem a experiência docente que as formatou; assim, elas não são inteiramente benéficas para os alunos pobres. No entanto, elas trazem tópicos de novidades os quais formadores e políticas públicas educacionais poderiam dar mais atenção. ${ }^{63}$ Não possuímos espaço para explorar essas novidades, apenas para citá-las. A primeira dessas novidades diz respeito à atuação com as comunidades. Se observarmos bem, os professores premiados por sua docência no Brasil e no mundo, bem como as escolas que se destacaram em seus projetos educativos, trazem essa marca. A segunda novidade é a emergência de uma pedagogia mais artesanal do que científica, ou seja, os professores atuam mais de maneira relacional e experimental do que por protocolos de aprendizagem. A terceira novidade se traduz na prática de projetos socioeducativos, portanto, projetos de intervenção social. Por fim, a quarta novidade trata-se de uma autorreflexão do professor e do aluno sobre a condição de pobreza em que se encontram, visando formas de superação.

Desconfiamos que essas quatro novidades presentes nas práticas docentes dos professores engajados, isto é, atuação em comunidades, educação experimental, projetos de intervenção social e autorreflexão, são quatro potentes lutas que se apresentam na docência atual. Como mencionamos, são lutas pontuais, e não gerais, não podendo ser atribuídas a todo e qualquer docente ou escola. Também não são, necessariamente, novas, mas se modernizam diante das urgências de hoje. Além disso, já se constituíram em espaços de disputa, pois escolas públicas, experimentais, privadas e ONG estão em seu encalço. Como exemplo, podemos citar as chamadas escolas inovadoras - noção totalmente plural, sobre a qual há várias interpretações -, uma vez que todas elas orbitam em torno desses elementos.

${ }^{63}$ FAVACHO (2019). 
O fato é que, se uma pesquisa deseja compreender as resistências docentes, terá que voltar às bases, ir lá onde os professores estão, lá onde estão, sobretudo, os professores que não desistiram de educar, os engajados em diferentes frentes de atuação, sejam elas quais forem. Uma vez lá, sua tarefa é tentar diagnosticar o sentido das micropolíticas docentes e transformar essas micropolíticas em filosofia analítica da política, como nos ensina Foucault. ${ }^{64}$ Mesmo que não estejamos em pleno acordo com essas novas (ou velhas) práticas docentes, elas podem nos fornecer pistas para compreendermos e enfrentarmos, daqui em diante, da melhor forma possível, as inúmeras demandas que daí decorrerão.

\section{Finalizações...}

Tentamos defender, neste artigo, que uma maneira potente de compreender a relação pobreza-educação (ou vice-versa) é pela prática histórica. Tal prática, da forma como Foucault a concebeu, implica compreender as ações tanto dos sujeitos como dos Estados ao longo dos tempos. Implica, portanto, saber como sujeito e Estado refletem sobre um certo fenômeno e como agem. Resulta daí, localizar os pontos em que eles podem se identificar ou se aproximar, mas também os pontos onde os sujeitos constroem suas linhas de fuga.

Nessa perspectiva, refletindo sobre o objeto deste artigo (pobrezaeducação), tanto o Estado como a experiência docente construíram formas gerais e específicas de governo de populações pobres. Se, por um lado, o Estado tende a se ocupar com a regulação da vida dos pobres a partir das demandas de mercado, por outro lado, os docentes engajados se mostram bastante solidários com as aflições das crianças e jovens pobres. Se, por um lado, o Estado tem insistido, historicamente, em um tipo de governo que, ao mesmo tempo, inclui e exclui as populações pobres da escola pública, por outro lado, os docentes continuam atuando sobre os alunos com elementos religiosos, humanistas, políticos e mercadológicos. Entendemos que enquanto os docentes não submeterem esses elementos a

${ }^{64}$ FOUCAULT (2004c) 
uma reflexão mais potente, estarão jogando o jogo do Estado enquanto pensam estar contra ele. Todavia, não se trata de diminuir o valor desses elementos, e sim de problematizá-los e potencializá-los. Porém, isso não se dará pela conscientização dos docentes sobre o que e como fazem para, então, agir. Trata-se, antes, de agir e, então, espantar-se com a maneira pela qual temos praticado uma educação para e com os pobres. Não se trata também de explicar para os docentes que é assim que eles agem, mas de eles mesmos se imporem a desconfortável tarefa do pensamento, que só poderá dar a eles uma única alternativa: engajar-se.

Quando os professores são engajados, eles podem, sim, instigar os alunos a procurarem também se engajarem na vida, pela vida, a favor da vida, a fim de gerar sentidos múltiplos para suas existências.

A expressão professores engajados é por nós valorizada porque desconfiamos que essa atitude, a atitude de engajar-se, de afetar-se por uma verdade é o que faz a resistência docente mostrar suas primeiras aparições. Por isso, as novidades docentes aqui destacadas, embora não representem resistências mais potentes, elas são, sim, pontos iniciais, possíveis, cotidianos, a partir dos quais, resistências podem se manifestar. Em nosso entendimento não se trata de ir em busca de grandes rupturas sociais. Podem vir assim? Sim, podem. Entretanto,

É mais comum [...] serem pontes móveis e transitórios, que introduzem na sociedade clivagens que se deslocam, rompem unidades e suscitam reagrupamentos, percorrem os próprios indivíduos, recortando-os e os modelando, traçando neles, em seus corpos e almas, regiões irredutíveis. ${ }^{65}$

Assim, Foucault nos dá a difícil tarefa de recolher essas pontes móveis, minúsculas e mal definidas, a fim de compor um diagnóstico do presente. A história desse presente na docência se apresenta, para nós, assim dispersa e permeada de práticas que ora nos aprisionam, ora nos libertam de alguma coisa, ora nos libertam de nós mesmos.

${ }^{65}$ FOUCAULT (1988, p. 91-92). 


\section{Referências}

ARROYO, M. Algumas questões sobre educação e enfrentamento da pobreza no Brasil. [Entrevista concedida a] Ana Maria Alves Saraiva. Em Aberto, Brasília, v. 30, n. 99, p. 147-158, mai./ago. 2017. https://doi.org/10.24109/2176-6673.emaberto.30i99.3253

AZEVEDO. C. M. M. de. Cota racial e Estado: abolição do racismo ou direitos de raça? Cadernos de Pesquisa, v. 34, n. 121, jan./abr., 2004. https://doi.org/10.1590/S0100-15742004000100010

AZEVEDO, Cecília. Guerra à pobreza: EUA, 1964. Revista de História, 153 (2 $\left.{ }^{\circ}-2005\right), \quad 305-323$. https://doi.org/10.11606/issn.23169141.v0i153p305-323

BIESTA, G. Para além da aprendizagem: educação democrática para um futuro humano. Tradução Rosaura Eichenberg. Belo Horizonte: Autêntica, 2013.

BUFFA, E.; NOSELLA, P. (1997). A educação negada: introdução ao estudo da educação brasileira contemporânea. São Paulo: Cortez, 1997.

BRAGA, A. C.; MAZZEU, F. J. C. O analfabetismo no Brasil: lições da história. RPGE- Revista on line de Política e Gestão Educacional, v. 21, n. 1, p. 24-46, 2017. https://doi.org/10.22633/rpge.v21.n1.2017.9986

BRITO, M. M. L. de. Juventude, pobreza e trabalho: desafios para o mundo contemporâneo. Dissertação de Mestrado. Universidade Estadual do Ceará - UECE - Pró-reitoria de Pesquisa e Pós-Graduação/Mestrado acadêmico em Políticas Públicas e Sociedade. Fortaleza/Ce, 2006.

CARVALHO, A. F. de. Foucault e a crítica à institucionalização da Educação: implicações para as artes de governo. Pro-Posições. Campinas, v. 25, n. 2 (74), p. 103-120, mai./ago. 2014. https://doi.org/10.1590/S0103-73072014000200006 
CUNHA, I. da S. A evolução das políticas de atendimento à infância no Brasil: entre concessões e o reconhecimento de direitos. REAe - Revista de Estudos Aplicados em Educação, v. 1, n. 2, ago./dez. 2016. https://doi.org/10.13037/rea-e.vol1n2.4323 https://doi.org/10.13037/reae.vol1n2.4323

CURY, C. R. J. A educação como desafio na ordem jurídica. In: LOPES, E. M.; FARIA FILHO, L. e VEIGA, C. (Orgs). 500 anos de educação no Brasil. Belo Horizonte: Autêntica, 2000.

CURY, Carlos Roberto Jamil. A educação básica como direito. Cad. Pesq, v. 38, n. 134, p. 293-303, ago. 2008. https://doi.org/10.1590/S0100$\underline{15742008000200002}$

DÁVILA, J. Diploma de brancura: política social e racial no Brasil 1917-1945. Tradução Claudia Sant'Ana Martins. São Paulo: Unesp, 2006.

DARDOT, P. e LAVAL, C. A nova razão do mundo: ensaio sobre a sociedade neoliberal. Tradução Mariana Echalar. São Paulo: Boitempo, 2016.

DUARTE, A. Foucault e os coletivos políticos: novas formas de vida para além do sujeito identitário de direitos. In: RESENDE, H. (Org.). Michel Foucault: política - pensamento e ação. Belo Horizonte: Autêntica, 2016.

FAVACHO, A. Currículo e subjetividade docente sem garantias. In MORGADO, José C.; SANTOS, Lucíola L. C. P; PARAISO, M. A. (org). Estudos Curriculares - um debate contemporâneo. Curitiba/PR: CRV, 2013.

FAVACHO, A. Experiência de si e docência. In ANDRADE, Ana P. (org). Formação, discursos e experiências docentes. Belo Horizonte/MG: Letramento, 2018.

FAVACHO, A. M. P. (2019). A docência como experiência ética: 
aproximações entre os estudos foucaultianos e a prática docente. Horizontes, 37, e019024. https://doi.org/10.24933/horizontes.v37i0.764

FERNANDES, F. A integração do negro na sociedade de classe. Volume 1. São Paulo: Globo, 2008.

FRIGOTTO. F (org.). Educação e crise do trabalho: perspectivas de final de século. Petrópolis, RJ: Vozes, 1998.

FOUCAULT, M. Microfísica do Poder. Tradução Roberto Machado. Rio de Janeiro: Graal, 2000.

FOUCAULT, M. Sobre as maneiras de escrever a história. In: Ditos e Escritos II. Foucault: Arqueologia das Ciências e História dos sistemas de pensamento. Organizado por Manuel Barros da Motta. Tradução Elisa Monteiro. Rio de Janeiro: Forense Universitária, 2000.

FOUCAULT, M. Retornar à História. In: Ditos e Escritos II. Foucault: Arqueologia das Ciências e História dos sistemas de pensamento. Organizado por Manuel Barros da Motta. Tradução Elisa Monteiro. Rio de Janeiro: Forense Universitária, 2000.

FOUCAULT, M. A ordem do discurso. Tradução Laura Fraga de Almeida Sampaio. São Paulo: Loyola, 2001.

FOUCAULT, M. A "Governamentalidade". I: Ditos e Escritos IV Foucault: estratégia, poder-saber. Organizado por Manuel Barros da Motta. Tradução Vera Lucia Avellar Ribeiro. Rio de Janeiro: Forense Universitária, 2003a.

FOUCAULT, M. Omnes et singulatim: uma crítica da razão política. In: Ditos e Escritos IV - Foucault: estratégia, poder-saber. Organizado por Manuel Barros da Motta. Tradução Vera Lucia Avellar Ribeiro. Rio de Janeiro: Forense Universitária, 2003b. 
FOUCAULT, M. A tecnologia política dos indivíduos. In: Ditos e Escritos V - Foucault: ética, sexualidade, política. Organizado por Manuel Barros da Motta. Tradução Elisa Monteira, Inês Autran Dourado Barbosa. Rio de Janeiro: Forense Universitária, 2004a.

what

FOUCAULT, Michel. A hermenêutica do sujeito. Tradução Márcio Alves da Fonseca e Salma Tannus Muchail. São Paulo: Martins Fontes, 2004b.

FOUCAULT, M. A filosofia analítica da política. In: Ditos e Escritos $V$ Foucault: ética, sexualidade, política. Organizado por Manuel Barros da Motta. Tradução Elisa Monteira, Inês Autran Dourado Barbosa. Rio de Janeiro: Forense Universitária, 2004c.

GADELHA, S. Desempenho, gestão, visibilidade e tecnologias como vetores estratégicos de regulação e controle de condutas na contemporaneidade. Educar em Revista, Curitiba, Brasil, n. 66, p. 113139, out./dez. 2017. https://doi.org/10.1590/0104-4060.54712

GENTILI, P. O direito à educação e as dinâmicas de exclusão na América Latina. Educ. Soc., Campinas, v. 30, n. 109, p. 1059-1079, set./dez. 2009. https://doi.org/10.1590/S0101-73302009000400007

HORTA, J. S. B. Direito à educação e obrigatoriedade escolar. Cad. Pesq., n.104, 1998.

KOMATSU, Bruno e outros. Novas medidas de educação e de desigualdade educacional para a primeira metade do Século XX no Brasil. Estud. Econ., São Paulo, v. 49, n. 4, p. 687-722, out./dez. 2019. https://doi.org/10.1590/0101-41614943bnpl

LUZ, k. Z. W. Do direito à educação ao direito à aprendizagem no pacto nacional pela alfabetização na idade certa. Dissertação (Mestrado). Universidade Estadual de Ponta Grossa - Setor de Ciências Humanas, Letras e Artes - Programa de Pós-Graduação em Educação, Ponta Grossa, 2017. 
MÜLLER, M.T. O Senai e a educação profissionalizante no brasil. Revista HISTEDBR On-line, Campinas, n. 40, p. 189-211, dez. 2010. https://doi.org/10.20396/rho.v10i40.8639814

MELLO E SOUZA, L. de. Desclassificados do ouro: a pobreza mineira no século XVIII. $2^{\mathrm{a}}$ ed. Rio de Janeiro: Graal, 1986.

NUNES, C. O "velho" e "bom" ensino secundário: momentos decisivos. Revista Brasileira de Educação, n. 14, mai./jun./jul./ago. 2000.

PEREIRA, J. M. M. O Banco Mundial e a construção político-intelectual do "combate à pobreza". Topoi, v. 11, n. 21, p. 260-282, jul./dez. 2010. https://doi.org/10.1590/2237-101X011021014

RIZZINI, I. O século perdido: raízes históricas das políticas públicas para a infância no Brasil. São Paulo: Cortez, 2011.

RODRÍGUEZ-AMAYA, C. (2017). Premio a la investigación e innovación educativa y pedagógica 2007-2015. Temas, motivaciones, preocupaciones y prácticas de los docentes innovadores de Bogotá. En Compilado de experiencias e investigaciones. Congreso Internacional. Desafios de la Innovación Educativa, 2017 (pp. 235-250). Bogotá: Dokuma.

RODRÍGUEZ-AMAYA, C. Docente emprendedor: urgencia, procedencia y emergencia de un nuevo ethos docente en Colombia (19602015). Doctorado Interinstitucional en Educación. Universidad Pedagógica Nacional. Bogotá, 2019. Tese

SPOSITO, M. P. O povo vai à escola - a luta popular pela expansão do ensino público em São Paulo. São Paulo: Loyola, 1984.

SCHUELER, A. F. M. de. Crianças e escolas na passagem do Império para a República. Rev. bras. Hist. [online], v. 19, n. 37, p. 59-84, sept. 
1999.

https://doi.org/10.1590/S0102-01881999000100004

PMid:22106507

VEIGA, C. A escolarização como projeto de civilização. Revista Brasileira de Educação, n. 21, set/out/nov/dez. 2002. https://doi.org/10.1590/S1413-24782002000300008

VEIGA, C. História da Educação. São Paulo: Ática, 2007.

VEIGA, C. Escola pública para os negros e os pobres no Brasil: uma invenção imperial. Revista Brasileira de Educação, v. 13, n. 39, set./dez. 2008. https://doi.org/10.1590/S1413-24782008000300007

VEIGA-NETO, Alfredo. Algumas raízes da Pedagogia moderna. In: ZORZO, Cacilda; SILVA, Lauraci D.; POLENZ, Tamara (Org.). Pedagogia em conexão. Canoas: Editora da ULBRA, 2004.

YANNOULAS, S. C.; ASSIS S. G.; FERREIRA K. M. Educação e pobreza: limiares de um campo em (re)definição. Revista Brasileira de Educação, Brasília, v. 17, n. 50, maio-ago. 2012. https://doi.org/10.1590/S1413-24782012000200005

YANNOULAS, S. C. Literatura recente sobre uma antiga problemática. In: YANNOULAS, S. C. (Coord.). Política educacional e pobreza: múltiplas abordagens para uma relação multideterminada. Brasília: Liber Livro, 2013a.

YANNOULAS, Silvia Cristina (coord.) Política educacional e pobreza: múltiplas abordagens para uma relação multideterminada. Brasília: Liber Livro, 2013b.

Data de registro: $14 / 05 / 2020$

Data de aceite: 02/10/2020 